\title{
POTENTIAL USE OF OLIVE OIL MILL WASTEWATER TO CONTROL PLANT PATHOGENS AND POST HARVEST DISEASES
}

\author{
Ioannis Vagelas $^{1 凶}$, Ioan Radu Sugar $^{2}$ \\ ${ }^{1}$ Department of Agriculture Crop Production and Rural Environment, University of Thessaly, Fytokou St., \\ N. Ionia, GR-38446 Magnesia, Greece \\ ${ }^{2}$ Technical University of Cluj-Napoca, Faculty of Engineering, Mechanical Engineering and Technological \\ Management Department, Str. Dr. Victor Babeș No. 62A, 430083 BAIA-MARE, Romania \\ 凶agelas@uth.gr \\ https://doi.org/10.34302/crpjfst/2020.12.4.14

Article history:
Received:
15 April 2020
Accepted:
10 December 2020
Keywords :
Olive oil mill wastewater,
Antifungal activity,
Plant and post-harvest
diseases. \\ Article history: \\ 15 April 2020 \\ 10 December 2020 \\ Keywords : \\ Olive oil mill wastewater \\ Antifungal activity \\ diseases.
}

\section{Introduction}

During olive oil extraction a large amount of solid and aqueous residues as olive oil mills wastewaters (olive OMWs) produced annually worldwide where the majority of it being produced in the Mediterranean basin. The uncontrolled disposal of olive OMW is becoming a serious environmental problem due to its high content of phenolic compounds: tannins and flavonoids (Gonzales et al. 1999; Hamdi, 1992). Some of these phenols are responsible for several biological effects, including antibiosis (Rodrvguez et al. 1988) and phytotoxicity (Capasso et al. 1992). They also appear to be involved in the defense of plants against invading pathogens, including bacteria, fungi and viruses (Marsilio et al. 2001). The use of olive OMW for plant and harvested fruit protection against microorganism could be a solution for residues management and nature protection. The main objective on this study was to examine the antifungal activity of olive OMW against plant pathogens and plant post-harvest diseases.

\section{Material and methods}

2.1.Effect of olive OMW on the mycelium growth of fungus

The antifungal effect of olive OMW against plant pathogens (Fusarium oxysporum f.sp. lycopersici, Pythium spp., Sclerotinia sclerotiorum and Verticillium dahliae) were tested in vitro. Tested were made on PDA (Potato Dextrose Agar; DIFCO). Treatments were PDA plates with a) olive OMW added into the medium and autoclaved and b) a drop of filter sterilized olive OMW (using a syringe filler $0.2 \mu \mathrm{m}$ ) added onto the agar surface. In the first treatment a $25 \mathrm{ml}$ of olive OMW were added into 11 agar and further sterilized by autoclaving $\left(120{ }^{\circ} \mathrm{C}\right.$ for $\left.20 \mathrm{~min}\right)$. In the second treatment a drop $(50 \mu \mathrm{l})$ of sterilized filtered olive OMW was added onto the centre of each plate. Fifteen agar plates per treatment, were inoculated with a mycelium plug ( $5 \mathrm{~mm}$ in diameter) of the above fungi (depended of the treatment) taken from the periphery of 7 days old fungal colonies. Mycelia plugs were placed onto the centre of each plate or next to the olive OMW drops. Equal plate 
numbers per fungus treatment were used as control (without olive OMW). Plates were incubated at $21^{\circ} \mathrm{C}$ for six days and fungi mycelium growth was recorded.

\subsection{Antimicrobial activity of olive OMW on fruits treated with pathogens}

Two common species of Penicillium $(P$. italicum and $P$. digitatum), isolated from mandarin fruits and Botrytis cinerea isolated from red horn (sweet) peppers were used for this experiment. Spores suspension was prepared by collecting spores of above Penicillium species, from 8 days old cultures. Three agar plates per fungus culture were used to collect spores. Spores were collected in 11 Erlenmeyer flask which contained distilled water by washing the agar surface with $3 \mathrm{ml}$ distilled water and filtered that solution throw sterilized muslin. In each flask spores suspension was adjusted at $10^{6}$ spores $/ \mathrm{ml}$. A $50 \mathrm{ml}$ of olive OMW were added in each flask. Mandarin fruits were surface sterilized and soaked for $3 \mathrm{~min}$ in 11 beakers contained $500 \mathrm{ml}$ of the above spore and olive OMW solution. After that time fruits removed from the flasks, dried for $10 \mathrm{~min}$ in a laminar flow unit and incubated at $21^{\circ} \mathrm{C}$ for 12 days. Olive OMW was passed through Whatman filter paper No 2 before added to each beaker. The same procedure was followed for red horn peppers inoculated with $B$. cinerea. After the incubation time, the spore number of each mandarin fruits or peppers were count by scraped each treated fruit surface into 11 beaker contained $500 \mathrm{ml}$ distill water. The spore number per treatment and per beaker was counted in optical microscope using a hematocytometer. The experiment had fourteen replicates per treatment and two treatments; infected with spores and olive OMW mandarin fruits and infected with spores and olive OMW red peppers. Equal numbers of mandarin fruits and red peppers soaked only in olive OMW and only in fungus spore suspension were used as control.

\subsection{Effect of olive OMW on tomato plants infected with Fusarium oxysporum f.sp. lycopersici}

In this experiment, two tomato varieties were used, cv. Roma and cv. Marmande. Plant pathogens used were $V$. dahliae and $S$. sclerotiorum, both isolated from tomato plants. For each variety, 42 tomato seedlings were incubated with spores $\left(10^{6}\right.$ conidia/ml $)$ of $V$. dahliae and 42 seedlings with $S$. sclerotiorum with mycelial suspension collected from 10 PDA petri dishes. In $V$. dahliae treatment from the 42 plants 21 of them were incubated in $V$. dahliae conidia suspension for $10 \mathrm{~min}$ and 21 were incubated in the conidial suspension treated with olive OMW $(5 \mathrm{ml} / 100 \mathrm{ml}$ in total solution). In $S$. sclerotiorum treatment, 21 tomato plants were incubated in S. sclerotiorum mycelial suspension for $30 \mathrm{~min}$ and 21 were incubated in mycelial suspension treated with olive OMW (5 $\mathrm{ml} / 100 \mathrm{ml}$ in total solution). Olive OMW was passed through Whatman filter paper No 2. All treated plants were planed into $250 \mathrm{ml}$ pots and kept in a glasshouse. Plants were harvested 45 days after planting and stem height were measured. Tomato plants (21plants/variety) were used as control.

\subsection{Statistical analysis}

Data were analyzed using the Minitab statistical package. Analysis of variance was used to assess treatments effect.

\section{Results and discussion}

\subsection{Effect of olive OMW on the mycelium growth of fungus}

There was a statistically significant difference between filtered olive OMW and control (untreated PDA and sterilized with olive OMW PDA), $(P<0.001)$. The filtered olive OMW inhibits the growth of all tested fungi mycelium (Fig. 1). Sterilized olive OMW had similar effect on the mycelia growth of Pythium spp., $V$. dahliae, $S$. sclerotiorum and $F$. oxysporum f.sp. lycopersici with the untreated control. However, sterilised olive OMW seems to have some positive effect on the mycelium growth of all tested fungi (Fig 1). 

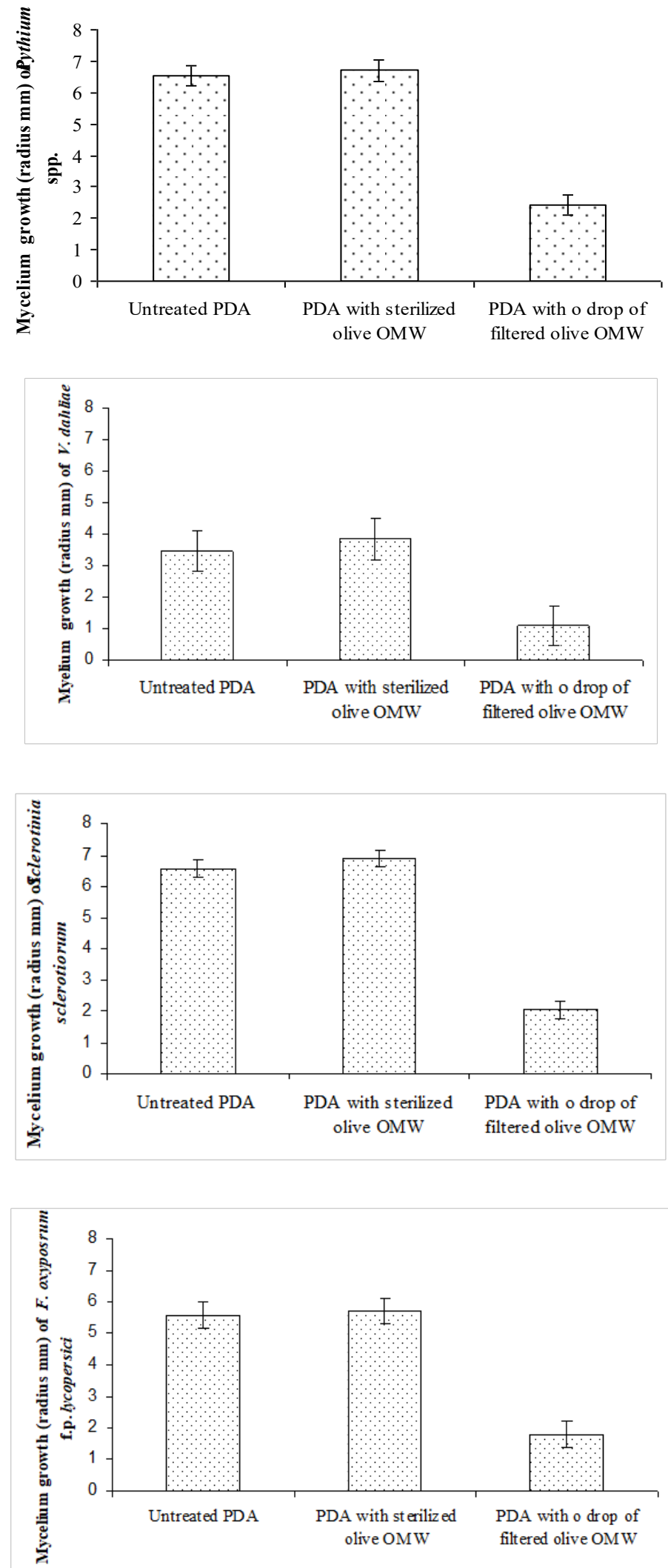

Figure 1. Effect of sterilized and filtered olive oil mill wastewater (olive OMW) on the mycelium growth of Pythium spp., $V$. dahliae, $S$. sclerotiorum and $F$. oxysporum f.sp. lycopersici. 


\subsection{Antimicrobial activity of olive OMW on} fruits treated with pathogens

The olive OMW reduced the number of Penicillium spp. $(\mathrm{P}<0.001)$ and $B$. cinerea $(P<0.001)$ spores from mandarin fruits and red peppers respectively. On mandarin fruits the average spore's number was $4,7 \times 10^{6}$ for mandarin fruits infected only with Penicillium species and $0,9 \times 10^{2}$ for mandarin fruits infected with Penicillium species and treated with olive OMW (Fig. 2). On red horn (sweet) peppers the average spore's number was $4.6 \times 10^{5}$ for peppers infected only with $B$. cinerea and $2,2 \times 10^{2}$ peppers infected with $B$. cinerea and treated with olive OMW.
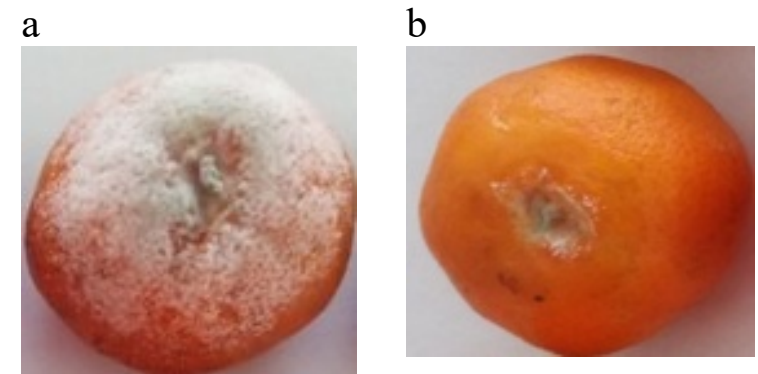

Figure 2. Mandarin fruits infected with Penicillium species only (a), with Penicillium species and treated with olive OMW (b).

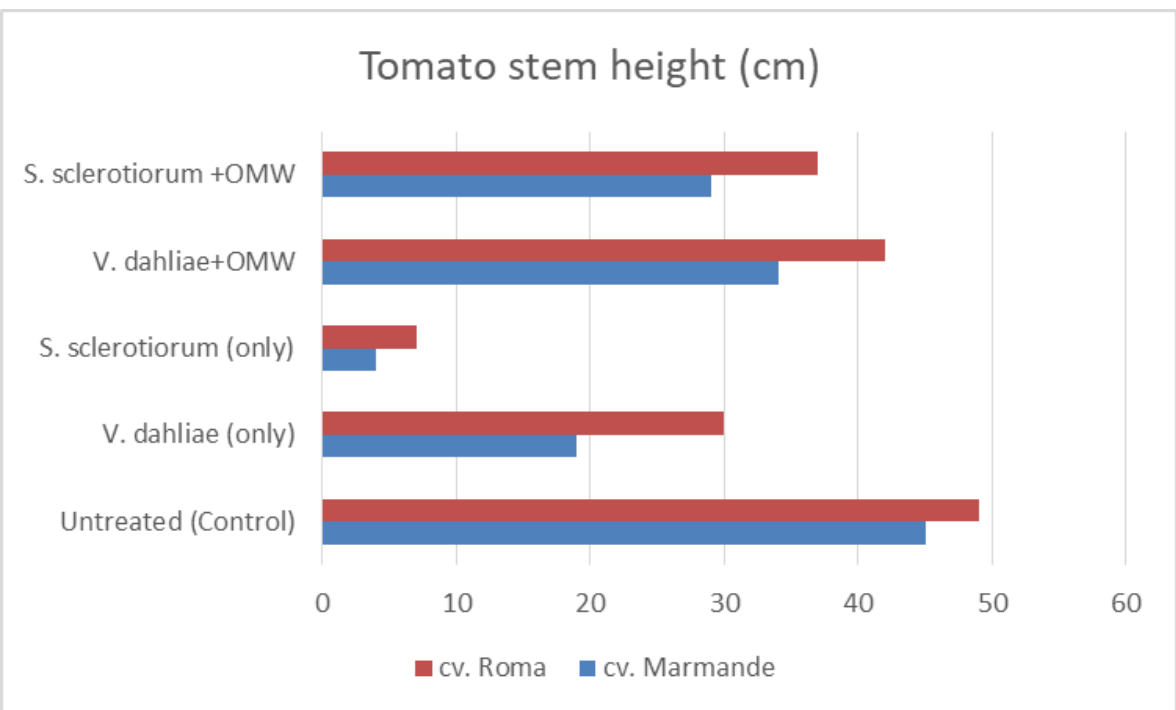

Figure 3. Effect of olive OMW on tomato stem height infected with $V$. dahliae spores or with $S$. sclerotiorum mycelia suspension.

\subsection{Effect of olive OMW on tomato plants infected with Fusarium oxysporum f.sp. lycopersici}

There was a statistically significant difference $\quad(P<0.001) \quad$ between untreated (Control) and treated plants with $V$. dahliae spores or S. sclerotiorum mycelia suspension on the height of tomato stem (Fig. 3). Olive OMW produced more plant biomass (shoot length) than those infected only with $V$. dahliae spores or with S. sclerotiorum mycelia suspension (Fig. $3)$.

\section{Conclusions}

Olive oil mill wastewater (olive OMW) contains phytotoxic components capable of inhibiting the growth of microorganisms (Ramos-Cormenzana et al. 1995) and plants (Martin et al., 2002). Olive OMW contains phenolic compounds (Ramos-Comenzana et al. 1995) polysaccharides, lipids, proteins, and a number of monocyclic and polymeric aromatic molecules (Ethaliotis et al. 1999) which might exhibit inhibition effects towards some specific microorganism populations. In the current study filtered sterilised olive OMW significantly reduced the growth of Pythium spp., V. dahliae, $S$. sclerotiorum and $F$. oxysporum f.sp. 
lycopersici. According to D'Annibale et al., (2004) phenolic compounds are the main determinants of the phytotoxic effect of olive residues. Thus, the phenolics of olive OMW used in this experiment had negative effect on all tested fungi in vitro. The used for olive OMW sterilization probably removed or destroyed the phenolic compounds from olive OMW solution resulted a same or a better growth media for all tested fungi in vitro. Furthermore, the production of the two species of Penicillium ( $P$. italicum and $P$. digitatum) and $B$. cinerea spores on fruits inhibited by olive OMW. We assume that the presence of phenolic compounds on olive OMW suppresses fungi reproduction and possible could offer a protection on fruits from post-harvest diseases. Tomato plants infected with $V$. dahliae spores or $S$. sclerotiorum mycelia suspension and treated with olive OMW produced well developed plants compared with the plants infected only with $V$. dahliae spores or S. sclerotiorum mycelia suspension. Same results have been reported (Bonanomi et al. 2006, Vagelas et al. 2009) for olive mill residues affect saprophytic growth and disease incidence of foliar and soilborne plant fungal pathogens same as Penicillium spp., $B$. cinerea, $V$. dahliae and $S$. sclerotiorum presented in this research. Overall, we believe that the olive OMW due to phenolics have antifungal activity and could possibly use against soil borne fungal pathogens and fruit parasites such as Penicillium spp., causing plant or post-harvest diseases, respectively.

\section{References}

Bonanomi, G., V. Giorgi, G. Del Sorbo, D. Neri and F. Scala. 2006. olive mill residues affect saprophytic growth and disease incidence of foliar and soilborne plant fungal pathogens. Agriculture Ecosystems and Environment 115, 194-200.

Capacco, R. Cristinzio, G. Evidente, A. and F. Scognamiglio. 1992. Isolation, spectroscopy and selective phytotoxic effects of polyphenols from vegetable waste waters. Phytochemistry 31, 4125-4128.

D’Annibale, A., R. Casa, F. Pieruccetti, M. Ricci and R. Marabottini. 2004. Lentinula edodes removes phenols from olive mill wastewater, impact on durum wheat (Triticum durum desf.) germinability. Chemosphere 54, 887-894.

Ethaliotis, C., K. Papadopoulou, M. Kotsou, I. Mari and C. Balis. 1999. Adaptation and population dynamics of Aztobacter vinelandii during aerobic biological treatment of olive mill wastewater. FEMS Microbiology Ecology 30, 301-311.

Gonzales, D.M., E. Moreno, Q.J. Sarmiento and R.A. Cormenzana. 1999. Studies on antibacterial activity of wastewaters from olive oil mills (Alpechin), Inhibitory activity of phenolic and fatty acids. Chemosphere 20, 423-432.

Hamdi, M. 1992. Toxicity and Biodegradability of olive mill wastewaters in batch anaerobic digestion. Applied Biochemistry \& Biotechnology 37, 155-163.

Marsilio, V., C. Campestre and B. Lanza. 2001. Phenolic compounds change during California-style ripe olive processing, Food Chemistry 74, 55-60.

Ramos-Comenzana, A., M. Monteolica-Sanchez and M.J. Lopez. 1995. Bioremediation of alpechin. International Biodeterioration \& Biodegradation 35, 249-268.

Rodrvguez, M.M., J. Purez, A. RamosCormenzana and J.Martvnez. 1988. Effect of extracts obtained from olive oil mill waste on Bacillus megaterium ATCC 33085. Journal of Applied Bacteriology 64, 219222.

Vagelas, I., H. Kalorizou, A. Papachatzis, and M. Botu. 2009. Bioactivity of Olive Oil Mill Wastewater against Plant Pathogens and Post-Harvest Diseases. Biotechnology \& Biotechnological Equipment 23(2), pp.1217-1219. 